\title{
Um olhar de gênero e de geração nos universos rurais
}

\author{
Gênero e geração em contextos \\ rurais.
}

SCOIT, Parry; CORDEIRO, Rosineide; MENEZES, Marilda (Org.).

Florianópolis: Mulheres, 2010.

Fruto de diferentes trajetórias acadêmicas, a coletânea Gênero e geração em contextos rurais discute temas como gênero e geração no universo rural, em distintos contextos rurais abrangendo todas as regiões do Brasil.

Abrindo a coletânea, Ellen Woortmann faz uma linha histórica dos estudos feministas no Brasil, mostrando as principais nuances que esses estudos apontavam e que rumos estão sendo explorados, fazendo uma breve introdução das discussões que na coletânea serão debatidas: o universo dos estudos rurais e as questões relacionadas ao gênero e à geração.

Parry Scott também faz breves reflexões logo no início da coletânea, antecipando assim algumas considerações que devem ser levantadas. Uma primeira consideração mostra que cada vez mais as mulheres participam ativamente dos movimentos sociais e essa participação implica diferenciações nos contextos familiares, dando maior espaço também para suas reivindicações.

Outro aspecto visto como importante por Scott é o foco das atenções dos pesquisadores, que cada vez mais se voltam para os jovens, os idosos e os próprios adultos que "enfrentam a reordenação das relações familiares, associadas à organização de atividades de produção, de consumo, de comercialização, de sucessão e de direitos".

As organizadoras da coletânea optam então por dividi-la em três blocos temáticos, agrupando assim artigos em cada uma dessas partes. A primeira parte foca a questão do "Poder, política e negociações", trazendo artigos que discutem a violência contra a mulher nesse contexto rural, assim como artigos que procuram demonstrar o impacto do Pronaf Mulher para as agricultoras e a importância das políticas discutidas no âmbito do Mercosul pensando as mulheres rurais.

Buscando compreender como se dá a violência contra a mulher, Parry Scott, Ana Cláudia Rodriguez e Jeíza Saraiva, em "Onde mal se ouvem os gritos de socorro: notas sobre a violência contra a mulher em contextos rurais, procuram verificar como a violência ocorre em relação às mulheres rurais, uma lacuna percebida nos estudos e nas pesquisas sobre a temática.

Tendo discutido a questão da violência contra a mulher no contexto rural e sendo verificado que o acesso da mulher às políticas públicas permite maior autonomia, Carmen Osorio Hernández faz uma análise teórica das políticas públicas para essas agricultoras em "Reconhecimento e autonomia: o impacto do Pronaf-Mulher para as mulheres agricultoras", mostrando algumas mudanças que vêm ocorrendo no cenário rural em decorrência do acesso das mulheres a esses benefícios governamentais.

Esse acesso às políticas públicas pode ser visto como uma faca de dois gumes; afinal, se por um lado pode permitir maior autonomia às mulheres agricultoras, por outro as mulheres 
podem ser vítimas desse acesso. É o caso daquelas agricultoras que acessaram o crédito e realizaram investimentos junto à produção leiteira, atividade proeminentemente feminina, mas que, à medida que foi incorporando novas tecnologias, foi se masculinizando.

Andrea Butto e Karla Hora apresentam uma última reflexão nesse primeiro bloco temático da coletânea, com o ensaio "Integração regional e políticas para as mulheres rurais no Mercosul", em que procuram analisar aspectos da formulação e da implementação de políticas públicas para as mulheres rurais no âmbito regional, a partir da Reunião Especializada sobre Agricultura Familiar (REAF) do Mercosul.

A segunda parte da coletânea trata da "Organização produtiva, gênero e divisão do trabalho" e reúne artigos que tratam das relações estabelecidas entre gênero, trabalho e pluriatividade, complementaridade de gênero e papel da mulher na manutenção da agrobiodiversidade, e também das relações de gênero e poder em assentamentos rurais.

"As problemáticas de gênero e geração nas comunidades rurais de Santa Catarina" são abordadas por Vilênia Aguiar e Valmir Stropasolas, que centram suas atenções nos principais aspectos relacionados à migração dos jovens no contexto rural.

Há ainda algumas questões ressaltadas no âmbito do gênero, tais como a falta de preparo gerencial ou até mesmo de estímulo para que as mulheres se envolvam com as questões relacionadas à gestão da propriedade, o controle contínuo dos pais e sua própria exclusão dos processos sucessórios.

Essas questões também estão presentes no artigo de Carolina Braz de Castilho Silva e Sergio Schneider, "Gênero, trabalho rural e pluratividade", que procura identificar as formas de inserção das mulheres rurais no mercado de trabalho em atividades não agrícolas e fora da propriedade familiar e suas consequências e efeitos sobre a unidade produtiva.

Novamente aqui a invisibilidade do trabalho feminino é colocada em evidência na discussão do lugar da mulher e na divisão do trabalho, mostrando que as mulheres estão presentes nos trabalhos produtivos dos empreendimentos rurais, sim, mas ainda carregam o peso de serem concebidas nessa esfera apenas como ajudantes do trabalhador masculino.

O trabalho das mulheres no contexto rural é também apreciado por Iraildes Caldas Torres e Luana Mesquita Rodrigues no texto "O trabalho das mulheres no sistema produtivo da várzea amazônica", contexto esse altamente demarcado pelas relações familiares na organização da economia doméstica local. Aqui também se procura revelar mais uma vez que o trabalho da mulher não é reconhecido, apesar de fundamental dentro da organização familiar.

Responsáveis pela alimentação familiar, plantam, cuidam das crianças, participam da colheita, preparam as refeições, arrumam e limpam a casa, lavam roupas e louças, cuidam do quintal e dos animais de pequeno porte, carregam ferramentas, limpam os roçados, participam de mutirões, e ainda assim seu trabalho não é visibilizado, são vistas como estando apenas "ajudando" seus maridos ou seus pais.

Fechando a série de artigos que procura verificar a organização produtiva das unidades rurais e a questão de gênero, Hersilia Cadengue Oliveira e Mariomar Almeida enfatizam o papel que as agricultoras ocupam nas unidades domésticas, verificando as relações de poder existentes no âmbito familiar e os projetos de vida que traçam em "Relações de gênero e poder no assentamento rural Araraíba da Pedra - Cabo de Santo Agostinho - Pernambuco".

As autoras se concentram em demonstrar a inserção e a integração das mulheres nas políticas públicas voltadas para a agricultura familiar e as consequências desse fenômeno no contexto familiar, apresentando um Brasil onde ainda se mostra presente a ideia de que a mulher é um apêndice do homem, especialmente nessa área.

Tendo estabelecido o papel do gênero nas organizações produtivas e a divisão do trabalho ali presente, a parte final da coletânea foca nas questões relacionadas às "Mobilidades, juventudes e relações interageracionais". Nela são apresentados os diferentes contextos migratórios no país, tentando desvelar o impacto dessa mobilidade generificada para os locais de origem desses migrantes, assim como para os locais de destino escolhidos.

Um primeiro contexto migratório envolvendo gênero é apresentado por Marcelo Saturnino Silva e Marilda Aparecida Menezes em "Homens que migram, mulheres que ficam: o cotidiano das esposas, mães e namoradas dos migrantes sazonais do município de Tavares - PB", enfocando a migração temporária de homens nordestinos para as lavouras de cana do Sudeste, retornando a seus locais de origem logo após a safra.

Silva e Menezes demonstram que a autonomia temporária dada às mulheres que ficam nos roçados enquanto seus homens 
migram é bastante superficial, pois essas continuam subordinadas a seus pais e maridos, que, mesmo a distância, são os tomadores de decisões da família no que se refere ao patrimônio e aos investimentos a serem realizados.

A análise dessas mulheres que decidem migrar, solteiras ou casadas, e as resultantes configurações sociais são abordadas por Maria Aparecida de Moraes Silva, Beatriz Medeiros Melo e Andréia Perez Appolinario em "Vidas em trânsito, mulheres dos cocais maranhenses nas periferias das cidades canavieiras paulistas".

As autoras observaram que muitas das mulheres que migram não fazem parte da força empregada nos canaviais, mas desempenham papéis fundamentais que asseguram a permanência da família, mantendo os vínculos com os locais de origem, assim como as mulheres que ficam também o fazem.

Focando a juventude, Maria de Assunção Lima Paulo, em "Juventude rural, sexualidade e gênero: uma perspectiva para pensar a identidade", tenta verificar como os jovens rurais se percebem como indivíduos, utilizando-se dos questionamentos envolvendo a sexualidade para perceber como essas jovens pensam suas identidades.

Já Arlene Renk, Rosana Maria Badalotti e Silvana Winckler centralizam suas preocupações com as mudanças socioculturais ocorridas nas relações de gênero em seu artigo "Mudanças socioculturais nas relações de gênero e intergeracionais: o caso do campesinato no Oeste Catarinense", focando seu estudo nas estratégias de reprodução social e de empoderamento das mulheres nessa região.

O artigo fala do controle masculino sobre as filhas mulheres, vigiando sua reputação moral para obter boas alianças matrimoniais, mas também do controle que a lgreja e a sociedade exercem sobre elas. As autoras tentam demonstrar ainda como as modificações associativas modificaram a situação da mulher no contexto rural, seja impulsionando a obtenção de documentação, seja na incorporação dessas mulheres nos grupos e nas lideranças rurais, como - Movimento de Mulheres Agricultoras (atual Movimento de Mulheres Camponesas) e o MST.

A pluriatividade é também abordada neste artigo, vista como uma estratégia que consegue conciliar o trabalho da unidade familiar com a venda da mão de obra assalariada, provocando alterações nos papéis na família. Dessa forma, os jovens que trazem renda para casa conquistam um diferente status na relação com o chefe da família, com quem passarão a negociar quanto e como aplicar na propriedade, modificando ainda o acesso a direitos, o que anteriormente era inconcebível.

Preocupados também com a juventude rural, Rosineide Meira Cordeiro e Marion Teodósio Quadros analisam as jovens agricultoras que engravidaram antes dos 16 anos de idade e que, por isso, não podem acessar o saláriomaternidade em "Jovens agricultoras, saláriomaternidade e o critério idade". Aqui a idade mínima imposta às beneficiárias do programa é questionada, dialogando com algumas ideias feministas sobre a maternidade, assim como com legislações que colocam a proteção da maternidade sob o prisma da proteção trabalhista e previdenciária.

O debate sobre a gravidez na adolescência é também levantado pelas autoras, considerando não somente as questões relacionadas à idade, mas os diferentes significados da gravidez para os jovens em diferentes contextos.

Celecina de Maria Veras Sales também foca as jovens moças rurais em "Mulheres jovens rurais: marcando seus espaços", tentando demonstrar o lugar social das mulheres jovens num assentamento rural do sertão cearense. Sales traça um breve histórico de como o movimento feminista foi ganhando força e de como as políticas públicas foram sendo construídas ao longo do tempo, mostrando a importância das lutas das mulheres camponesas pelo reconhecimento civil e trabalhista, pelo direito de ter o título da terra e por participação política.

A condição juvenil só começa a ser contemplada a partir da década de 1990, levantada por alguns pesquisadores que perceberam dificuldades como falta de emprego, violência e outras demandas da juventude que começam a ter visibilidade.

Procurando analisar as mudanças no discurso e nas intervenções dos jovens assistidos por uma ONG feminista contra a violência de gênero, Hulda Stadtler e Marcílio José Silva, em "Ações educativas de uma ONG feminista em zona rural e mudanças no discurso local de jovens", finalizam a coletânea mostrando uma experiência de sucesso.

Neste artigo, Stadtler e Silva anteveem o poder de atuação que as ONGs assumem na sociedade por estarem em contato direto com as carências vividas pelas comunidades e como a ação de uma ONG de abordagem feminista pode ser determinante na mudança dos discursos dos jovens da região em que atua.

Políticas públicas, negociações, organizações produtivas, juventude e mobilidade, 
considerando gênero e geração, são devidamente aprofundadas na coletânea, mostrando diversas nuances de um contexto rural tão diversificado em sua geografia, mas com similaridades que ultrapassam fronteiras estaduais e que unem uma diversidade de mulheres jovens e adultas, abrindo a discussão para profícuos debates futuros.

Marie-Anne Stival Pereira e Leal Lozano Universidade Federal de Santa Catarina 